\title{
TRANSCERVICAL EXTENDED MEDIASTINAL LYMPHADENECTOMY (TEMLA) FOR STAGING OF NON-SMALL-CELL LUNG CANCER (NSCLC)
}

\author{
Marcin ZIELINSKI ${ }^{1}$, Lukasz HAUER ${ }^{1}$, Jolanta HAUER, Tomasz NABIALEK ${ }^{2}$, Artur SZLUBOWSKI², \\ Juliusz PANKOWSKI ${ }^{3}$ \\ 1Department of Thoracic Surgery, Pulmonary Hospital, Zakopane, Poland \\ ${ }^{2}$ Department of Anesthesiology and Intensive Care, Pulmonary Hospital, Zakopane, Poland \\ ${ }^{3}$ Department of Pathology, Pulmonary Hospital, Zakopane, Poland \\ e-mail: marcinz@mp.pl \\ doi:10.5152/tcb.2011.06
}

\section{INTRODUCTION}

There is a general agreement that, in the treatment of Non-Small-Cell Lung Cancer (NSCLC), the patients with stage I and II disease should undergo primary radical surgery. The patients with stage III (N2) disease discovered preoperatively should be treated with neoadjuvant chemotherapy or chemo-radiotherapy and subsequently operated on.

Therefore, the mediastinal staging plays a central role in the optimal choice of the most suitable treatment modality for patients with $\operatorname{NSCLC}(1,2)$.

The therapeutic impact of mediastinal lymphadenectomy on late survival rate is very possible but not finally proven (3-6). In recent years a new imaging technique, Positron Emission Tomography with Computer Tomography (PET/CT) and endoscopic techniques, including Endobronchial Ultrasonography with Transbronchial Fine Needle Biopsy (EBUS/TBNA) and Endoesophageal Ultrasonography and Fine Needle Aspiration (EUS) have been developed (7-9). However, invasive techniques remain a cornerstone of preoperative mediastinal staging (2). The methods of preoperative invasive staging of the mediastinum include classic cervical mediastinoscopy or videomediastinoscopy, Videothoracoscopy (VTS), anterior mediastinotomy, Video-Assisted Mediastinoscopic Lymphadenectomy (VAMLA) and Transcervical Extended Mediastinal Lymphadenectomy (TEMLA), introduced by the first author of this article (MZ) 7 years ago for staging and possibly to improve the results of treatment of NSCLC (10-14).

\section{Surgical technique of TEMLA}

During TEMLA all mediastinal lymph nodal stations and the surrounding fatty tissue are removed with the exception of the pulmonary ligament, station 9 nodes. The operation starts from the 5 to $8 \mathrm{~cm}$ collar incision in the neck.

Subplatysmal flaps are widely dissected and the muscles and vascular structures are widely liberated for better exposure during the procedure.

Visualization of both laryngeal recurrent nerves is obligatory in every case (Fig. 1, 2). The left recurrent nerve is especially endangered during the procedure, so it must be dissected very delicately and carefully protected from injury. Circumferential dissection of the nerve is not advisable, and preservation of the final layer of fascia covering the nerve is preferable.

Both vagus nerves must also be found. The right vagus nerve lies between the right carotid artery and right internal jugular vein (Fig. 3). The position of the left vagus nerve is similar. The vagus nerves are important landmarks for further dissection in the mediastinum.

Generally, the major sectionof TEMLA is an open procedure, with the exception of dissection of the subcarinal, station 7 , periesophageal, station 8 nodes and the left lower paratracheal, station 4 nodes, which are dissected in the mediastinoscopy-assisted fashion with the aid of the Linder-Dahan two-blade mediastinoscope (Richard Wolf, Knittlingen, Germany). The paraaortic, station 6 and aorta-pulmonary window, station 5 nodes are sometimes dissected with the aid of a videothoracoscope introduced to the mediastinum through the operative wound. 


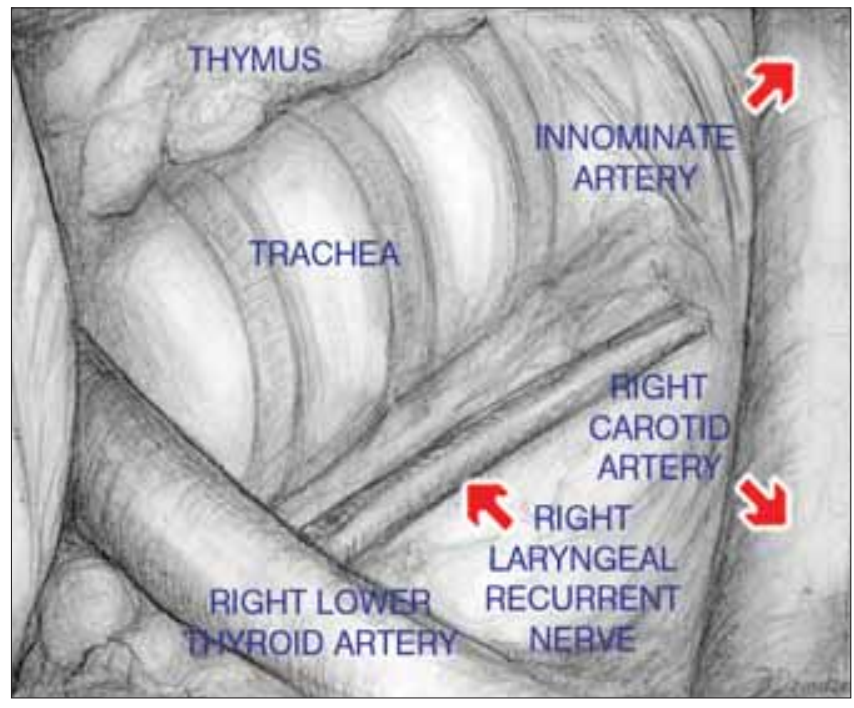

Figure 1. With the permission of EACTS Multimedia Man Cardiothorac Surg

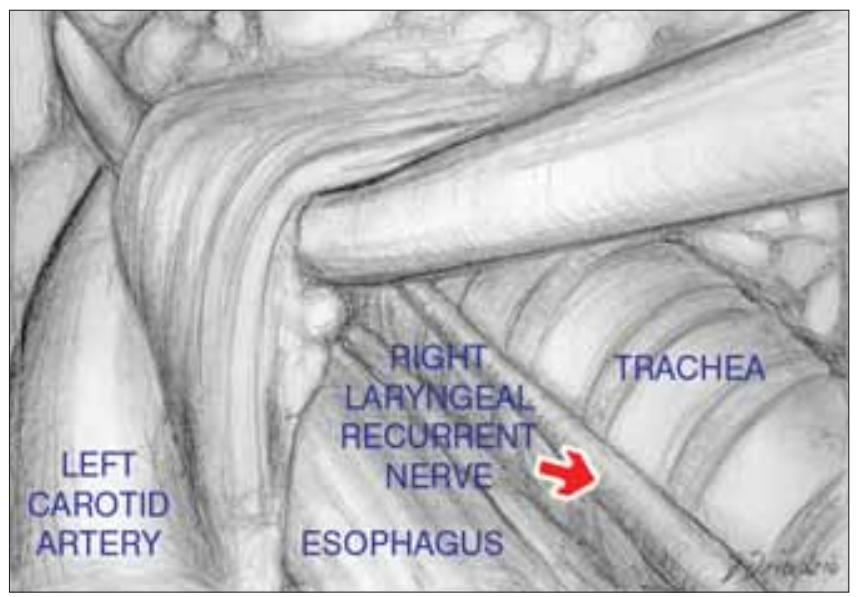

Figure 2. With the permission of EACTS Multimedia Man Cardiothorac Surg

Bilateral supraclavicular lymphadenectomy and even deep cervical lymph node dissection is possible during TEMLA through the same incision.

The mediastinal dissection begins with the removal of the highest mediastinal, station 1 lymph nodes lying above the left innominate vein. Resection of the upper poles of the thymus at the level of the left innominate vein improves access to the mediastinum (Fig. 4).

The next step is a dissection of the right paratracheal space, which proceeds along the posterior wall of the Superior Vena Cava until the azygos vein becomes visible. Right upper paratracheal, station $2 \mathrm{R}$ nodes located above the apex of the aortic arch and below the left innominate vein are dissected and removed (Fig. 5).

The lower paratracheal, station $4 \mathrm{R}$ nodes are dissected from the trachea, right main bronchus, Superior Vena Cava, azygos vein, ascending aorta and right mediastinal pleura (Fig. 6).

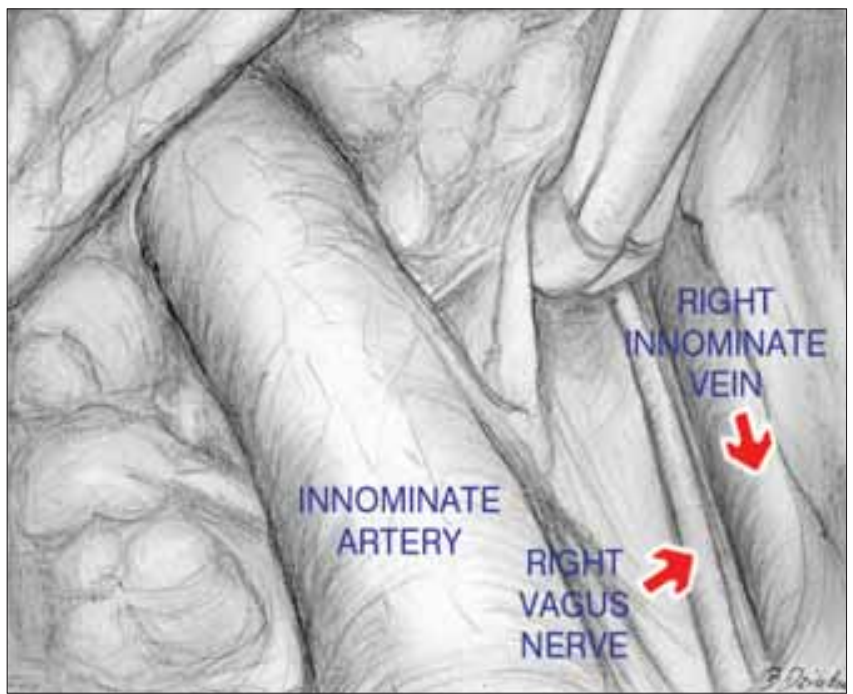

Figure 3. With the permission of EACTS Multimedia Man Cardiothorac Surg

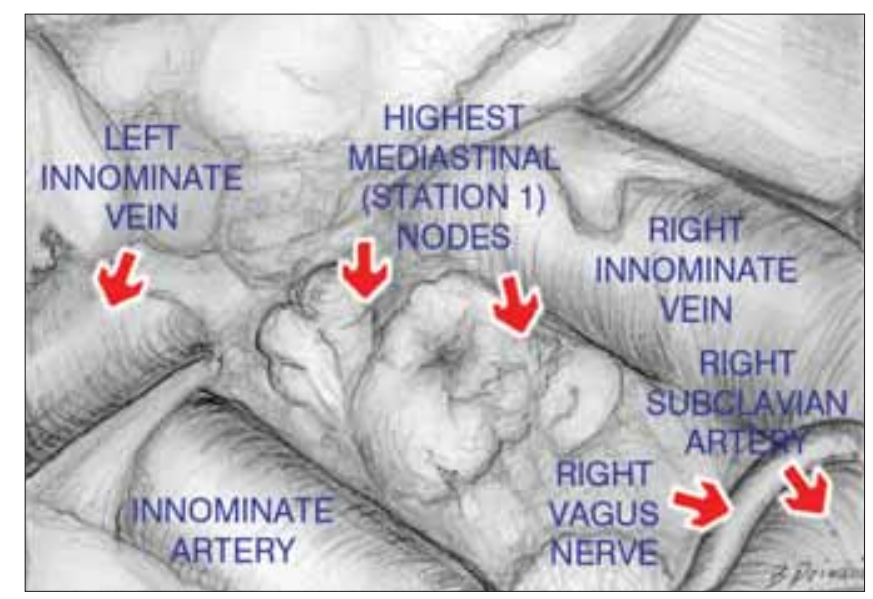

Figure 4. With the permission of EACTS Multimedia Man Cardiothorac Surg

Very occasionally, retrotracheal, station 3P nodes are found and removed (Fig. 7). We never found any metastatic lymph node in this station

In the right sided tumors the next step is a dissection of the prevascular station $3 \mathrm{~A}$ nodes, located in front of the Superior Vena Cava, to the right of the ascending aorta (Fig. 8). This station is never involved in the left sided tumors.

In my opinion, dissection of the left paratracheal nodes is the most difficult and risky part of TEMLA, because these nodes lie in close proximity to the left recurrent nerve. Generally, the left upper paratracheal station $2 \mathrm{~L}$ nodes lie in front of the nerve and the left lower station $4 \mathrm{~L}$ nodes lie behind the nerve (Fig. 9, 10).

During dissection of the subcarinal station 7 nodes the fascial layer covering the nodes must be divided. Usually, a prominent bronchial artery crossing the operating field must be clipped and divided. 


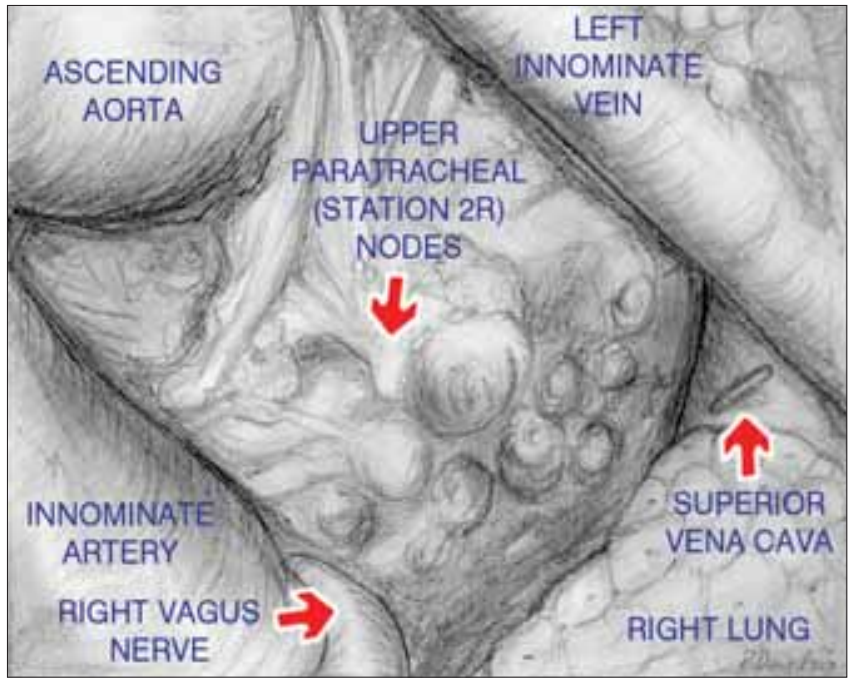

Figure 5. With the permission of EACTS Multimedia Man Cardiothorac Surg

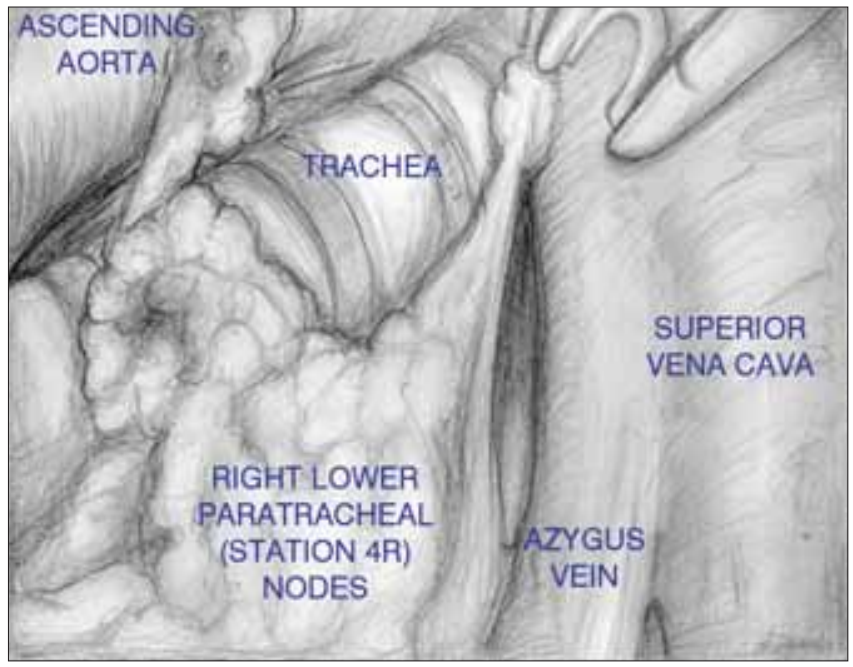

Figure 6. With the permission of EACTS Multimedia Man Cardiothorac Surg

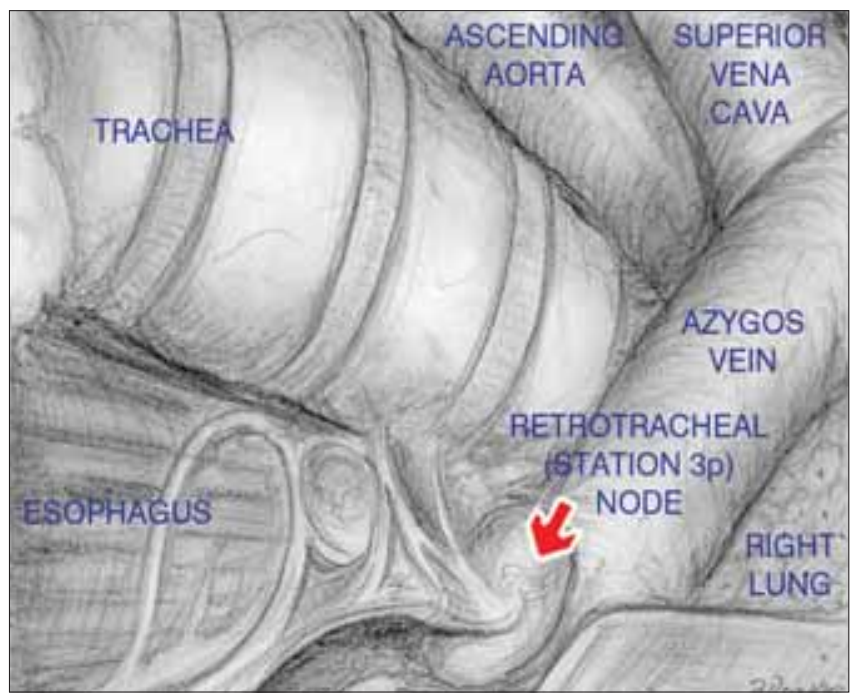

Figure 7. With the permission of EACTS Multimedia Man Cardiothorac Surg

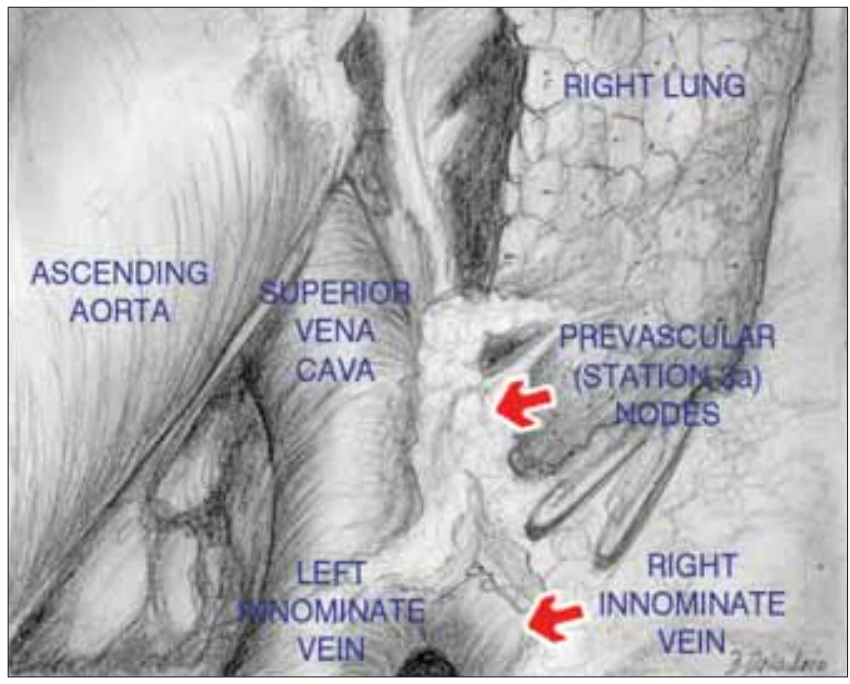

Figure 8. With the permission of EACTS Multimedia Man Cardiothorac Surg

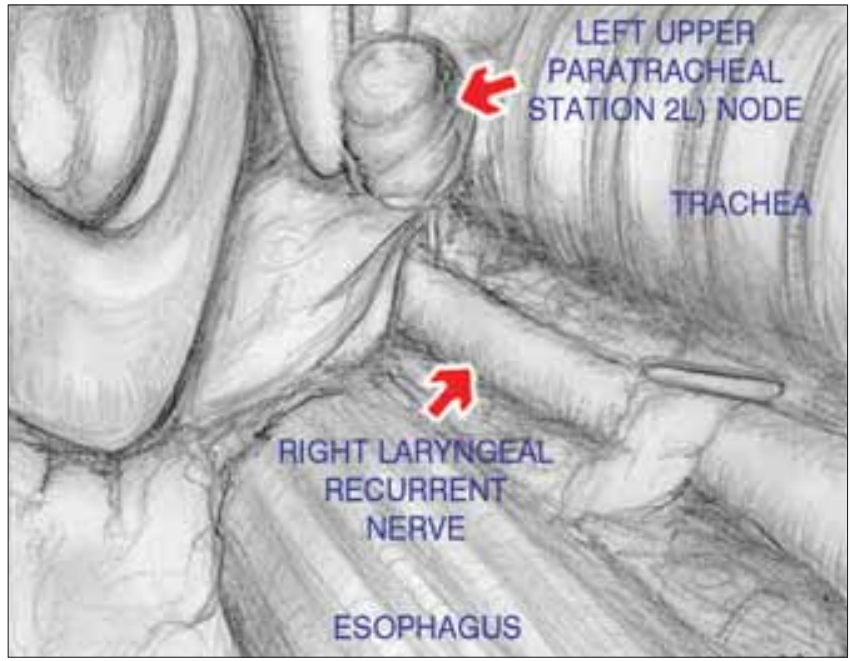

Figure 9. With the permission of EACTS Multimedia Man Cardiothorac Surg

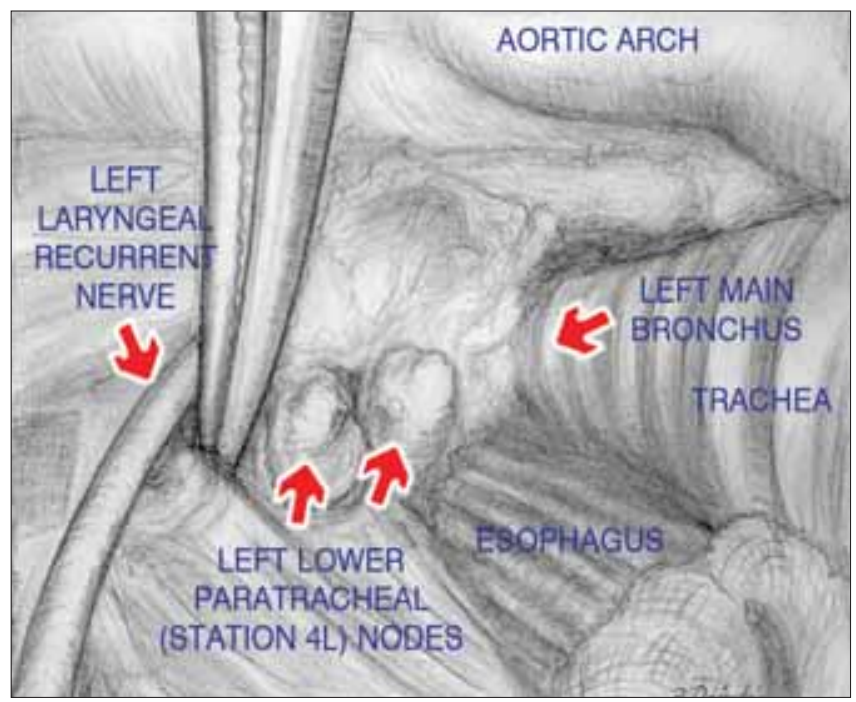

Figure 10. With the permission of EACTS Multimedia Man Cardiothorac Surg 
The subcarinal nodes must be dissected from the trachea, main bronchi, esophagus and main pulmonary arteries. After completion of this part of the operation, the tracheal bifurcation, both main bronchi, both pulmonary arteries, pericardium covering the left atrium, right superior pulmonary vein and right upper lobe bronchus become clearly visible. (Fig. 11).

In some patients, but not in all patients, the periesophageal, station 8 nodes are found and removed.

Dissection of the station $4 \mathrm{~L}$ nodes is performed in the mediastinoscopy-assisted fashion after completion of the dissection of stations 7 and 8 .

The entrance to the aorta-pulmonary window contain stations 6 and 5 which lie between the left innominate vein and left carotid artery. The left vagus nerve is a landmark for dissection. Division of the fascial layer between the left carotid artery and the left innominate vein facilitates entrance to the aorta-pulmonary window (Fig. 12).

At first, the adipose tissue is dissected from the wall of the ascending aorta down to the level of the left pulmonary artery with a peanut sponge (Fig. 13). Medial retraction of the ascending aorta is a safe maneuver facilitating access to the aorta-pulmonary window.

In some patients complete mobilization of the left innominate vein is necessary to obtain a good access to the para-aortic, station 6 nodes above the vein.

The whole fatty tissue from the aorta-pulmonary window space is removed. Any blood vessel crossing the space is clipped and divided.

Dissection proceeds along the left vagus nerve. The fatty tissue is then dissected from the left mediastinal pleura until the clear pleura and underlying left lung become clearlyl visible (Fig. 14). The left pulmonary artery, left phrenic nerve and left superior pulmonary vein are clearly visible after completion of dissection. In case of opening of the mediastinal pleura there is no need for drainage of the mediastinum. Insertion of a piece of fibrin sponge and hyperinflation of the lungs during closure of the wound is all that is necessary in such patients.

Currently, the indications for TEMLA in NSCLC in our department include preoperative staging of potentially operable patients, regardless of the mediastinal nodal status on Computer Tomography (CT) or Positron Emission Tomography/Computer Tomography (PET/CT), with the exception of patients with positive results of prior Endobronchial Ultrasonography/Transbronchial Needle Aspiration (EBUS/TBNA) or Endoesophageal Ultrasonography/ Fine Needle Aspiration (EUS/FNA).

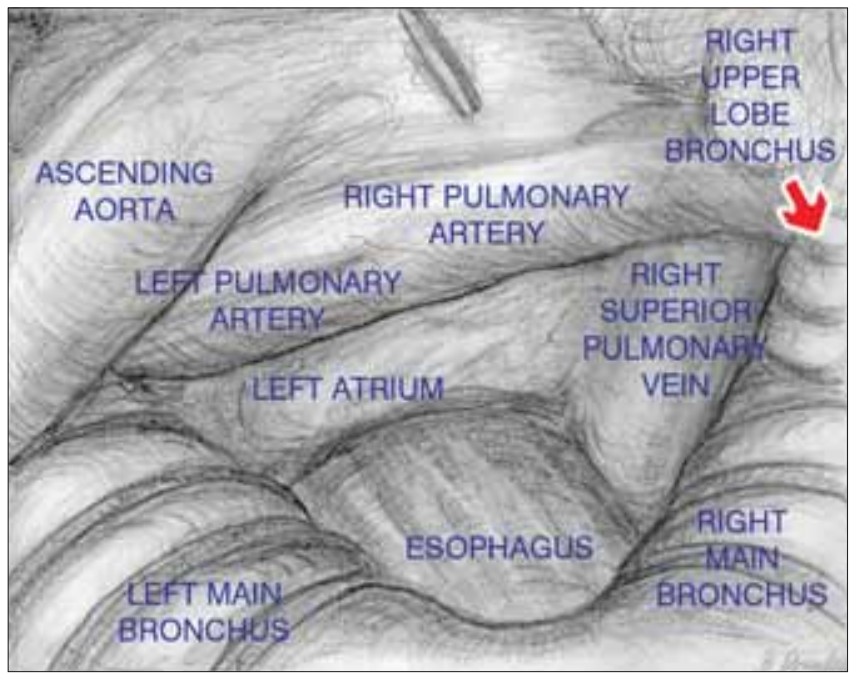

Figure 11. With the permission of EACTS Multimedia Man Cardiothorac Surg

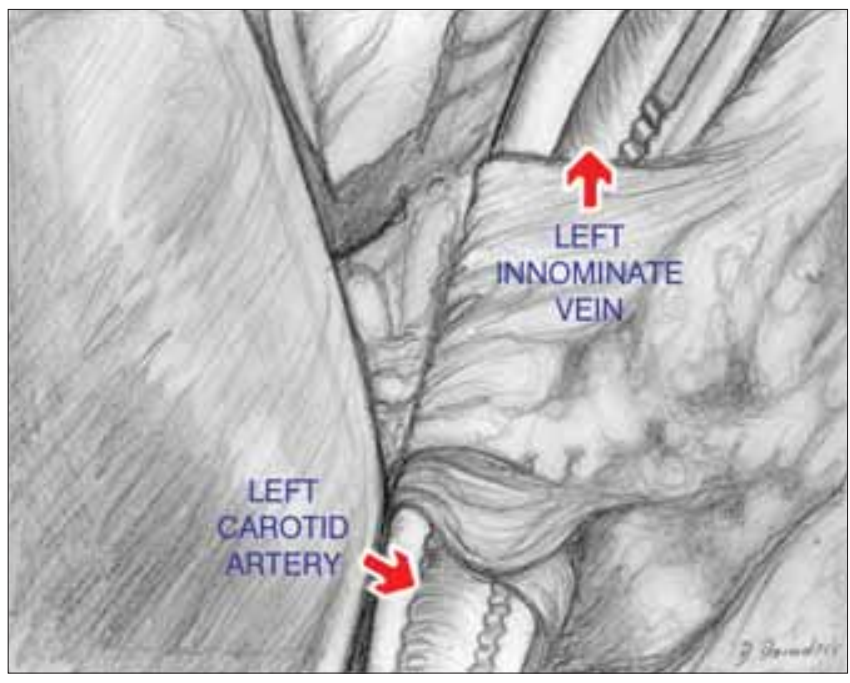

Figure 12. With the permission of EACTS Multimedia Man Cardiothorac Surg

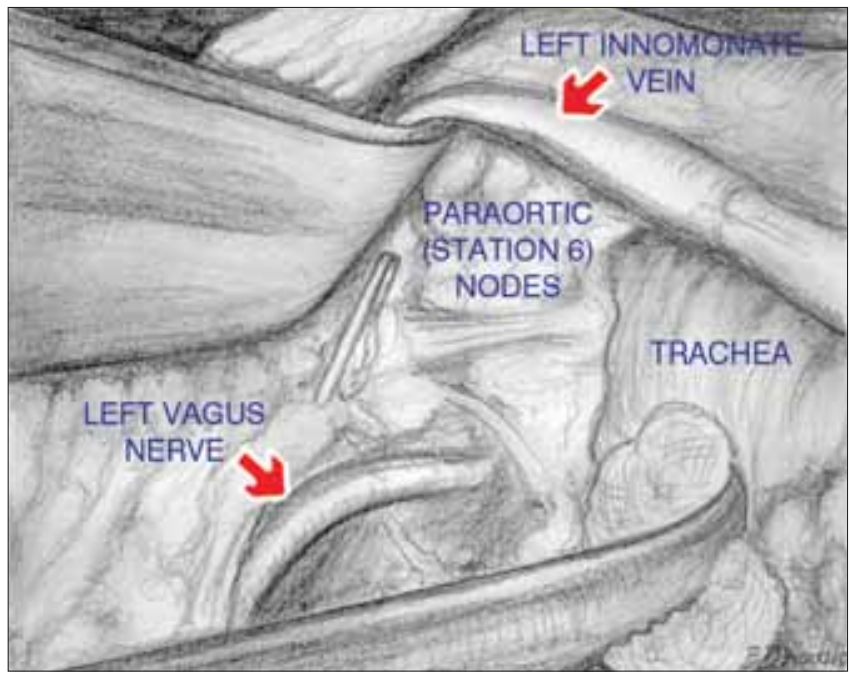

Figure 13. With the permission of EACTS Multimedia Man Cardiothorac Surg 


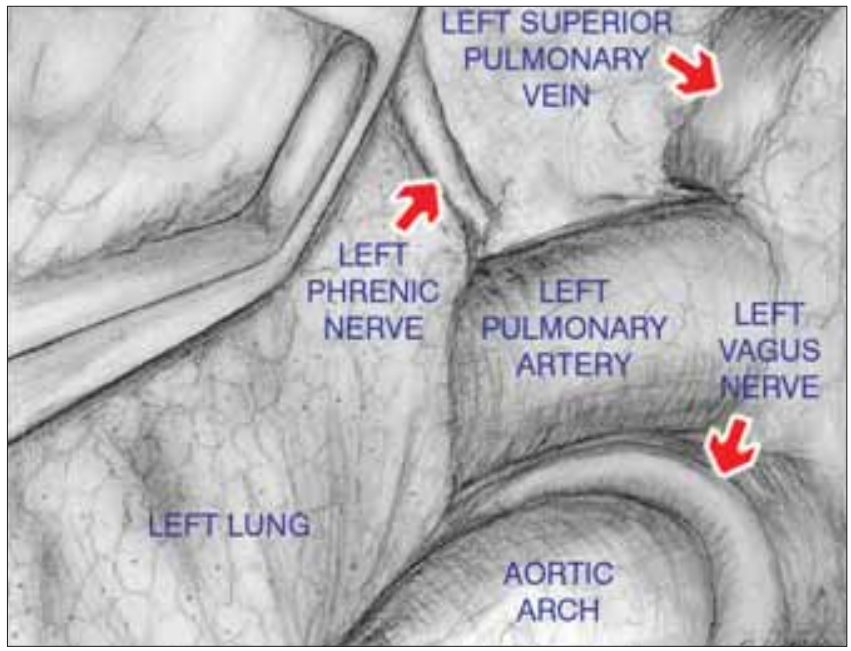

Figure 14. With the permission of EACTS Multimedia Man Cardiothorac Surg

\section{RESULTS}

TEMLA was performed on 698 patients, 577 men and 121 women aged between 41-79 years (mean age 62.8) from 1.1.2004 to 31.1.2010. There were 501 squamous-cell carcinomas, 144 adenocarcinomas, 25 large cell carcinomas and 28 others. Time of operation was 50 to $330 \mathrm{~min}$ (mean $128 \mathrm{~min}$ ). In the last 100 patients, the mean time of operation was $106.5 \mathrm{~min}$. There was small injury of the right main bronchus managed with fibrin sponge packing and no other intraoperative injuries of the vitally important structures including major vessels, tracheobronchial tree or the esophagus. There were 5 postoperative deaths unrelated to the procedure (mortality $0.7 \%$ ). Complications of TEMLA occurred in 46/698 of patients (6.6\%) with temporary laryngeal nerve palsy in $17 / 698$ patients $(2.4 \%)$ and permanent nerve palsy in $2 / 698$ patients $(0.3 \%)$ (Table 1). Pneumothorax necessitating pleural drainage occurred in $1 / 698$ patients $(0.1 \%)$, pleural effusion in $15 / 698$ patients (2.1\%). Asymptomatic widening of the mediastinum was noted in $40 \%$ of patients. It did not necessitate treatment, and subsided after several days and was not regarded as a postoperative complication.

The number of dissected nodes during TEMLA was 15 to 85 (mean 37.9). Metastatic N2 nodes were found in 159/698 patients (22.8\%) and N3 nodes were found in $26 / 698$ patients (3.7\%). Metastatic nodes were most prevalent in station 7 , station $4 \mathrm{R}$, station $2 \mathrm{R}$, station 5 and station 4L. Subsequent thoracotomy was performed in $445 / 513$ patients (86.7\%) after negative results of TEMLA.

There were 110 pneumonectomies, 37 sleevelobectomies, 280 lobectomies/bilobectomies, 3 sublobar resections and 15 explorations (3.4\%) (Table 2).
The mortality was $4.3 \%$ in 2004 and $1.2 \%$ in the years 2005-2009. In the period 2002-3, before the introduction of TEMLA, the postoperative mortality in our department was $3.5 \%$. The number of pulmonary resections for NSCLC in the years 2004-2005 decreased to $25 \%$ in comparison to the period 2002-3 (6).

During thoracotomy, omitted N2 was found in $7 / 445$ (1.6\%) patients and omitted normal mediastinal nodes were found in $53 / 445$ patients (11.9\%). Omitted metastatic N2 nodes were found in the station 5 (2 patients), station 4L (1 patient), station 7 (1 patient), station 4R (1 patient), station 8 (1 patient) and station 9 (1 patient).

Sensitivity of TEMLA in the discovery of N2-3 nodes was $96.4 \%$, specificity was $100 \%$, accuracy was $98.9 \%$, Negative Predictive Value (NPV) was 98.6\% and Positive Predictive Value (PPV) was 100\%

\section{COMMENT}

The main advantage of TEMLA for staging NSCLC is the possibility for removing almost all mediastinal lymph nodes with the surrounding fatty tissue. Mean number of 38.9 nodes/procedure were removed (from 15 to 85 nodes/procedure). Such complete removal of the mediastinal nodes increases the reliability of staging. No other invasive staging technique enables such complete assessment of the mediastinal nodes. For comparison, a mean number of 8.7-20.7 nodes was removed during VAMLA $(13,14)$. During mediastinoscopy, normally, 1-2 lymph nodes from each of five stations are accessible in this procedure (stations $2 \mathrm{R}, 4 \mathrm{R}$, $2 \mathrm{~L}, 4 \mathrm{~L}$ and 7 ) and mean number of $1-2$ nodes were biopsied during EBUS and EEUS procedures $(8,9,15)$. In 7 patients who underwent TEMLA omitted N2 nodes were found during subsequent thoracotomy (16). The reasons for omitting these nodes were related to the learning curve, in the last one hundred TEMLA procedures there were no false negative results and all diagnostic parameters of TEMLA were $100 \%$ for this large subgroup.

In our recently presented prospective randomized trial, diagnostic accuracy of TEMLA proved to be statistically better than in standard mediastinoscopy (sensitivity $100 \%$ vs. $37.5 \%$; NPV $100 \%$ vs. $66.7 \%$; $\mathrm{p}<0.05$ (17). The impairment of pulmonary function after TEMLA and standard mediastinoscopy, reflecting invasiveness of both surgical procedures, were not statistically different (18). Also the morbidity of TEMLA in the current study was relatively low. Most of the complications were minor and subsided during the follow-up period and there were no life-threatening 
intraoperative complications. Two of five postoperative deaths can be attributed to the progression of cancer (fatal hemorrhage secondary to the fistula between the pulmonary artery and the bronchial tree) and two others were independent events (myocardial infarct and intracerebral hemorrhage). In one patient the cause of death was unknown since the postmortem was not obtained. These data showed that the invasiveness of TEMLA was limited. Despite moderate invasiveness TEMLA is a relatively time consuming procedure, however it was well tolerated by the patients. Current mean operative time has been substantially reduced, however, from 160 to 112 minutes, due to the growing experience of the surgeons in our team.

Due to very liberal inclusion criteria to TEMLA there was a considerable number of patients who did not undergo subsequent thoracotomy after negative result of TEMLA (operability $86.7 \%$ ). Results of 445 patients who underwent thoracotomy indicate that previous TEMLA was not an obstacle to performing safely all kinds of pulmonary resections, including sleeve-lobectomies and pneumonectomies.

Diagnostic yield of TEMLA for NSCLC was very high and, if the results of the last one hundred patients were analyzed, all the diagnostic parameters were $100 \%$ (Table 3). False negative results of TEMLA were noted mostly in our early experience and were due to the learning curve.

In our recent study we showed that TEMLA had a significantly higher diagnostic yield than all other mediastinal staging modalities (PET/CT, EBUS, EUS, and remediastinoscopy). The results of future studies will show if TEMLA should be considered the gold standard of mediastinal nodal restaging after neoadjuvant therapy in patients with NSCLC (19)

Possible higher postoperative mortality and morbidity of pulmonary resections after prior TEMLA due to the inflammation and scarring of the mediastinal tissue was our concern initially, after the introduction of TEMLA. However, the postoperative mortality in 2004 , the first year when TEMLA was used, was $4.3 \%$, and in the years 2005-9, the postoperative mortality decreased to $1.1 \%$. In the period 2002-3, before introduction of TEMLA the postoperative mortality in our department was $3.5 \%$. These data indicate that introduction of TEMLA is not associated with increased risk of postoperative mortality but, conversely, it leads to decrease in the mortality, probably due to better selection of patients for pulmonary resection. Due to more accurate preoperative staging there was a $25 \%$ decrease in the number of pulmonary resections for NSCLC after the introduction of TEMLA.
Table 1. Complications of 698 TEMLA procedures

\begin{tabular}{lc}
\hline Complication & N (\%) \\
\hline Pleural effusion (conservative treatment) & $12(1.7)$ \\
Laryngeal recurrent nerve palsy- overall & $16(2.3)$ \\
Temporary left laryngeal recurrent nerve palsy & $2(0.3)$ \\
Temporary right laryngeal recurrent nerve palsy & $1(0.1)$ \\
Temporary bilateral laryngeal recurrent nerve palsy & $2(0.3)$ \\
Permanent laryngeal recurrent nerve palsy & $2(0.3)$ \\
Pneumothorax (necessitating chest drainage) & $1(0.1)$ \\
Pneumothorax (conservative treatment without & $3(0.4)$ \\
chest drainage) & \\
Respiratory insufficiency (ventilator) & $5(0.7)$ \\
Postoperative psychosis & $2(0.3)$ \\
Perforation of the duodenal ulcer & $1(0.1)$ \\
Cerebral ischemia & $1(0.1)$ \\
Subarachnoid hemorrhage & $1(0.1)$ \\
Cardiovascular insufficiency & $1(0.1)$ \\
Overall morbidity & $46(6.6)$ \\
Death1 & $5(0.7)$
\end{tabular}

Causes of death: exsanguinating respiratory hemorrhage on late date after procedure (2 patients), intracranial hemorrhage (1 patient), myocardial infarct (1 patient), unknown (1 patient)

Table 2. Types of pulmonary resections in 445 patients operated on after negative result of TEMLA

\begin{tabular}{|lc|}
\hline Type of pulmonary resection & Number of patients \\
\hline Pneumonectomy & 110 \\
Sleeve-lobectomy & 37 \\
Lobectomy/bilobectomy & 280 \\
Sublobar resection & 3 \\
Exploratory thoracotomy & 15 \\
Overall & 445 \\
\hline
\end{tabular}

In addition to the staging of NSCLC, TEMLA might have a therapeutic impact. Our preliminary late results are encouraging. Survival rates of patients who underwent radical $\mathrm{RO}$ resection after negative TEMLA are probably better than our previous results of survival for patients who were operated on before the introduction of TEMLA. Additionally, locoregional recurrence occurred in only 5 patients while all other recurrences 
Table 3. Diagnostic yield of TEMLA for NSCLC

\begin{tabular}{|lc|}
\hline Diagnostic Parameter & Value (\%) \\
\hline Sensitivity & 96.4 \\
Specificity & 100 \\
Negative Predictive Value (NPV) & 98.6 \\
Positive Predictive Value (PPV) & 100 \\
Accuracy & 98.8 \\
\hline
\end{tabular}

occurred in distal organs (predominantly in the brain, the bones and the liver). It is however too early to finally estimate the probable therapeutic impact of TEMLA in the treatment of NSCLC.

\section{REFERENCES}

1. Lardinois D, De Leyn P, Van Schil P, Porta RR, Waller D, Passlick B et al. ESTS guidelines for intraoperative lymph node staging in non-small cell lung cancer. Eur J Cardiothorac Surg. 2006; 30: 787-92. [CrossRef]

2. De Leyn $P$, Lardinois D, Van Schil PE et al. ESTS guidelines for preoperative lymph node staging for non-small cell lung cancer. Eur J Cardiothorac Surg. 2007; 32: 1-8. [CrossRef]

3. Wright G, Manser R, Byrnes G, Hart D, Campbell: Surgery for non-small cell lung cancer: systematic review and meta-analysis of randomized controlled trials. Thorax 2006; 61: 597-603. [CrossRef]

4. Passlick B, Kubuschock B, Sienel W, Thetter O, Pantel K, Izbicki J. Mediastinal lymphadenectomy in non-small cell lung cancer: effectiveness in patients with or without nodal micrometastases - results of a preliminary study. Eur $\mathrm{J}$ Cardiothorac Surg 2002; 21: 520-6. [CrossRef]

5. Wu Y, Huang Z, Wang S, Yang X, Qu W. A randomized trial of systematic nodal dissection in resectable NSCLC. Lung Cancer 2002; 36: 1-6. [CrossRef]

6. Lardinois D, Suter H, Hakki H, Rousson V, Betticher D, Ris HB. Morbidity, survival, and site of recurrence after mediastinal lymph-node dissection versus systematic sampling after complete resection for non-small cell lung cancer. Ann Thorac Surg. 2005; 80: 268-74. [CrossRef]

7. Cerfolio R, Buddhiwardhani $O$, Bryant $A$, Raghuveer $V$, Mountz J, Bartolucci A. The accuracy of integrated PETCT compared to dedicated PET alone for the staging of patients with Nonsmall Cell Lung Cancer. Ann Thorac Surg 2004; 78: 1017-23. [CrossRef]

8. Herth F, Ernst A, Eberhardt R, Vilman P, Dienemann H, Krasnik M. Endobronchial ultrasound-guided transbronchial needle aspiration of lymph nodes in the radiologically normal mediastinum. Eur J Respir 2006; 28: 910-4. [CrossRef]

9. Annema J, Hoeksstra O, Smit E, Veselic M, Versteegh M, Rabe K. Toward a minimally invasive staging strategy in NSCLC: analysis of PET positive lesions by EUS-FNA. Lung Cancer 2004; 44: 53-60. [CrossRef]

10. Kuzdzal J, Zielinski M, Papla B et al. Transcervical extended mediastinal lymphadenectomy--the new operative technique and early results in lung cancer staging. Eur $\mathrm{J}$ Cardiothorac Surg 2005; 27: 384. [CrossRef]

11. Mountain CF, Dresler CM. Regional lymph node classification for lung cancer staging. Chest 1997; 111: 1718. [CrossRef]

12. Zielinski M, Kuzdzal J, Nabialek T, Hauer L, Pankowski J, Dziadzio B. Transcervical extended mediastinal lymphadenectomy. Multimedia Manual of Cardiothoracic Surgery. MMCTS (October 9, 2006).

13. Hurtgen M, Friedel G, Toomes H, Fritz P. Radical videoassisted mediastinoscopic lymphadenectomy (VAMLA) technique and first results. Eur J Cardiothorac Surg 2002; 21: 348-51. [CrossRef]

14. Leschber G, Holinka G, Linder A: Video-assisted mediastinoscopic lymphadenectomy (VAMLA)--a method for systematic mediastinal lymphnode dissection. Eur J Cardiothorac Surg. 2003; 24: 192-5. [CrossRef]

15. Venissac N, Alifano M, Mouroux J: Video-assisted mediastinoscopy: experience from 240 consecutive cases. Ann Thorac Surg. 2003; 76: 208-12. [CrossRef]

16. Zielinski M. Transcervical extended mediastinal lymphadenectomy: results of staging in two hundred fifty-six patients with non-small cell lung cancer. J Thorac Oncol. 2007; 2: 370-2. [CrossRef]

17. Kuzdzal J, Zielinski M, Papla B et al. The Transcervical Extended Mediastinal Lymphadenectomy (TEMLA) versus cervical mediastinoscopy in NSCLC staging. Eur J Cardiothorac Surg 2007; 31: 88-94. [CrossRef]

18. Kuzdzal J, Zielinski M, Papla B et al. Effect of bilateral mediastinal lymphadenectomy on pulmonary function. Eur $\mathrm{J}$ Cardiothorac Surg. 2007; 31: 161-6. [CrossRef]

19. Zielinski M, Hauer L, Hauer J, Nabialek T, Szlubowski A, Pankowski J. Non-small-cell lung cancer restaging with transcervical extended mediastinal lymphadenectomy. Eur J Cardiothorac Surg. 2010; 37: 776-80. [CrossRef] 